
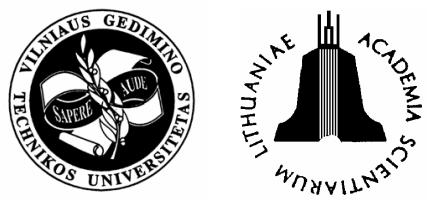

\title{
DYNAMICS DESIGN OF MECHANISM OF CRANE TROLLEY MOVEMENT
}

\author{
Vladimir Demokritov, Aleksandr Oleshkevich
}

Dept of Foundations of CarDesigning, Ulyanovsk State Technical University, Severny Venetz Str. 32, 432027 Ulyanovsk, Russia. Phone +7 (8 422) 435460; Fax +7 (8 422) 430237. E-mail: oav@ulstu.ru

Received 3 July 2006, accepted 4 September 2006

\begin{abstract}
A crane trolley with a hanging oscillating load was considered. Normal and tangential acceleration of the load and difference between the weight of the load and the strain of the rope are taken into account. Three differential dynamic equations were made. After the solution of the system one nonlinear equation was got; the solution of it was found. Frequency of own vibrations, amplitude and phase were defined taking primary conditions into consideration. The condition of resonance prevention was revealed.
\end{abstract}

Keywords: load, rope, crane, trolley, vibration, frequency.

\section{Introduction}

The named problem was considered in the works of M. S. Komarov [1] and S. A. Kazak [2] but there are some inaccuracies, for example:

- for the definition of a horizontal projection of the rope strain (the strain itself was counted equal to the weight of the load);

- normal acceleration of the vibrating load was not taken into account;

- for the deriving differential equations sometimes the functions from the other part of the article were used relating to the other schemes and other primary conditions;

- the conditions of resonance were formulated indefinitely.

An attempt to eliminate these inaccuracies was undertaken in the present paper.

\section{Mathematical model}

Rated scheme is presented in Fig 1.

The following signs are accepted:

$m_{1}$ - mass of the trolley;

$x_{1}$ - movement of the trolley;

$F$ - motive force;

$W$ - force of the resistance;

$m_{2}$ - mass of the load;

$G$ - weight of the load;

$N$-strain of the rope;

$\varphi$ - angle of the rope deflection;

$\ddot{x}_{1}$ - figurative acceleration of the trolley;

$a^{n}$ - normal acceleration of the relative load movement; $a^{t}$ - tangential acceleration of the relative load movement;

$l$ - length of the rope.

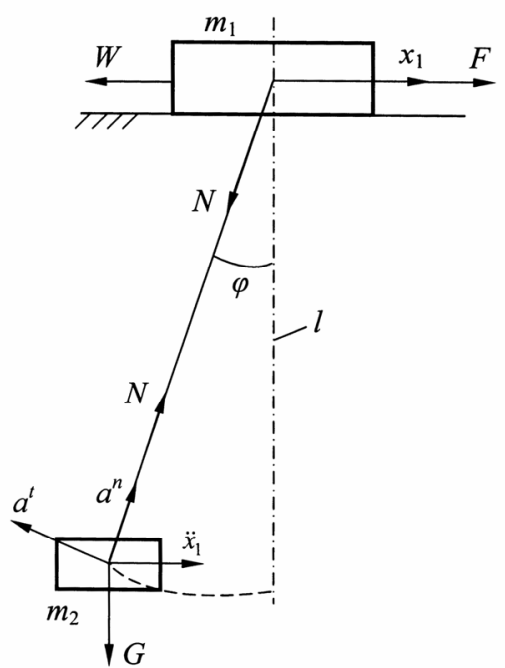

Fig 1. Rated scheme of a trolley with a load

Absolute acceleration of the load is:

$$
\bar{a}_{a b s}=\overline{\ddot{x}}_{1}+\bar{a}^{n}+\bar{a}^{t} \text {. }
$$

Then we take into account:

$$
\begin{aligned}
& \sin \varphi \approx \varphi ; \\
& \cos \varphi=1 ; \\
& a^{n}=\frac{v^{2}}{l}=\dot{\varphi}^{2} \cdot l,
\end{aligned}
$$

where $\dot{\varphi}$ - angle speed of the load; $v$ - linear speed of the load.

Horizontal projections of accelerations are:

$$
a_{x}^{n}=a^{n} \sin \varphi \approx \varphi \cdot \dot{\varphi}^{2} \cdot l \text {; }
$$




$$
a_{x}^{t}=-a^{t} \cos \varphi \approx-\ddot{\varphi} \cdot l
$$

where $\ddot{\varphi}$ - angle acceleration.

Vertical projections of accelerations are:

$$
\begin{aligned}
& a_{y}^{n} \approx \dot{\varphi}^{2} \cdot l ; \\
& a_{y}^{t} \approx \varphi \cdot \ddot{\varphi} \cdot l .
\end{aligned}
$$

We shall receive the system of three nonlinear differential equations:

$$
\left\{\begin{array}{l}
N \cdot \varphi-m_{2} \cdot \ddot{x}_{1}-\varphi \cdot l \cdot \dot{\varphi}^{2} \cdot m_{2}+m_{2} \cdot l \cdot \ddot{\varphi}=0 \\
-G+N-m_{2} \cdot \dot{\varphi}^{2} \cdot l-m_{2} \cdot \ddot{\varphi} \cdot \varphi \cdot l=0 \\
F-W-N \cdot \varphi-m_{1} \cdot \ddot{x}_{1}=0
\end{array}\right.
$$

where (1), (2) - differential equations of the movement of the load; (3) - differential equation of the movement of the trolley.

Expressing the strain $N$ from (2) and putting it into (1) and (3) we receive the system of two equations and at last excluding $\ddot{x}_{1}$ we come to one nonlinear equation:

$$
\begin{aligned}
& \ddot{\varphi} \cdot \varphi^{2} \cdot m_{2} \cdot l \cdot\left(1+\frac{m_{2}}{m_{1}}\right)+\ddot{\varphi} \cdot m_{2} \cdot l+\varphi \cdot \dot{\varphi}^{2} \cdot l \cdot \frac{m_{2}^{2}}{m_{1}}+ \\
& \varphi \cdot G \cdot\left(1+\frac{m_{2}}{m_{1}}\right)-\frac{m_{2}}{m_{1}}(F-W)=0 .
\end{aligned}
$$

We present a solution of this equation in the same function as with motionless point of hanging [3]:

$$
\varphi=\alpha \cdot \sin (k \cdot t+\beta),
$$

where own frequency of vibration $k$, amplitude $\alpha$ and first phase $\beta$ will be determined in the primary conditions. we have:

After putting the function (5) to equation (4)

$$
\begin{aligned}
& -\alpha^{3} \cdot k^{2} \sin ^{3}(k \cdot t+\beta) \cdot m_{2} \cdot l \cdot\left(\frac{m_{2}}{m_{1}}+1\right)- \\
& \alpha \cdot k^{2} \sin (k \cdot t+\beta) \cdot m_{2} \cdot l+ \\
& \alpha^{3} \cdot k^{2} \cos ^{2}(k \cdot t+\beta) \sin (k \cdot t+\beta) \cdot l \cdot \frac{m_{2}^{2}}{m_{1}}+ \\
& \alpha \cdot \sin (k \cdot t+\beta) \cdot G \cdot\left(1+\frac{m_{2}}{m_{1}}\right)-\frac{m_{2}}{m_{1}} \cdot(F-W)=0 .
\end{aligned}
$$

If the function (5) satisfies equation (4), we can expect that a sum of similar first and fourth parts of the equation (6) is equal to zero:

$$
\begin{aligned}
& -\alpha k^{2} \sin (k \cdot t+\beta) \cdot m_{2} \cdot l+ \\
& \alpha \sin (k \cdot t+\beta) \cdot G \cdot\left(1+\frac{m_{2}}{m_{1}}\right)=0,
\end{aligned}
$$

from where:

$$
k=\sqrt{\frac{g}{l} \cdot\left(1+\frac{m_{2}}{m_{1}}\right)},
$$

where $g$-acceleration of gravity.

Other authors $[1,2]$ came to the same expression by the other rated schemes and conclusions.

Putting expression (5) in the equation (2) we receive the strain of the rope:

$$
N=G+m_{2} \cdot l \cdot \alpha^{2} \cdot k^{2} \cdot \sin (2 \cdot k \cdot t+2 \cdot \beta) .
$$

From the primary condition with $t=0 \quad N=G$ we receive:

$$
\cos (2 \cdot \beta)=0, \text { that is } \beta=\pi / 4 \text {. }
$$

Then:

$$
N=G-m_{2} \cdot l \cdot \alpha^{2} \cdot k^{2} \sin (2 \cdot k \cdot t) .
$$

Equating the sum of the remaining first, third and fifth parts of expression (6) to zero we have:

$$
\alpha=\sqrt{\frac{F-W}{k^{2} \cdot m_{1} \cdot l \cdot \sin \left(k \cdot t+\frac{\pi}{4}\right) \cdot\left(\cos ^{2}\left(k \cdot t+\frac{\pi}{4}\right) \cdot \frac{m_{2}}{m_{1}}-\sin ^{2}\left(k \cdot t+\frac{\pi}{4}\right) \cdot\left(\frac{m_{2}}{m_{1}}+1\right)\right)}}
$$

and $\varphi=\alpha \cdot \sin \left(k \cdot t+\frac{\pi}{4}\right)$.

With the extreme meanings:

$$
\sin \left(k \cdot t+\frac{\pi}{4}\right)=1 \text { and } \sin \left(k \cdot t+\frac{\pi}{4}\right)=-1
$$

we receive maximum angle:

$$
\varphi_{\max }=\sqrt[3]{\frac{F-W}{k^{2} \cdot l \cdot\left(m_{1}+m_{2}\right)}} .
$$

\section{Conclusion}

1. Own vibrations of the system with frequency $k$ are forced through a frame of the crane trolley and passed across the axle-boxes to the axes of wheels, which have their own frequency of bending vibrations.

2. A condition $p \neq(0,7 \ldots 1,3) \cdot k$ must be fulfilled for the prevention of resonance.

3. A quantity $p$ depends on the construction of movement mechanism.

\section{References}

1. Komarov, M. S. The dynamics of the carrying machines (Динамика грузоподъемных машин). Moscow-Kiev: Mashgiz, 1962. 267 p. (in Russian).

2. Kazak, S. A. The foundations of design of the crane mechanisms (Основы проектирования и расчета крановых механизмов). Krasnojarsk: Krasnojarsk University, 1987. 181 p. (in Russian).

3. Strength, stability, vibrations / Under the editorship of Birger, I. A.; Panovko, I. G. (Прочность, устойчивость, колебания), Vol 3, Moscow: Mashinostrojenije, 1968. 569 p. (in Russian). 